Supplement of

\title{
A new perspective of permafrost boundaries in France during the Last Glacial Maximum
}

Kim H. Albers et al.

Correspondence: Kim H. Albers (kim.albers@kit.edu) 

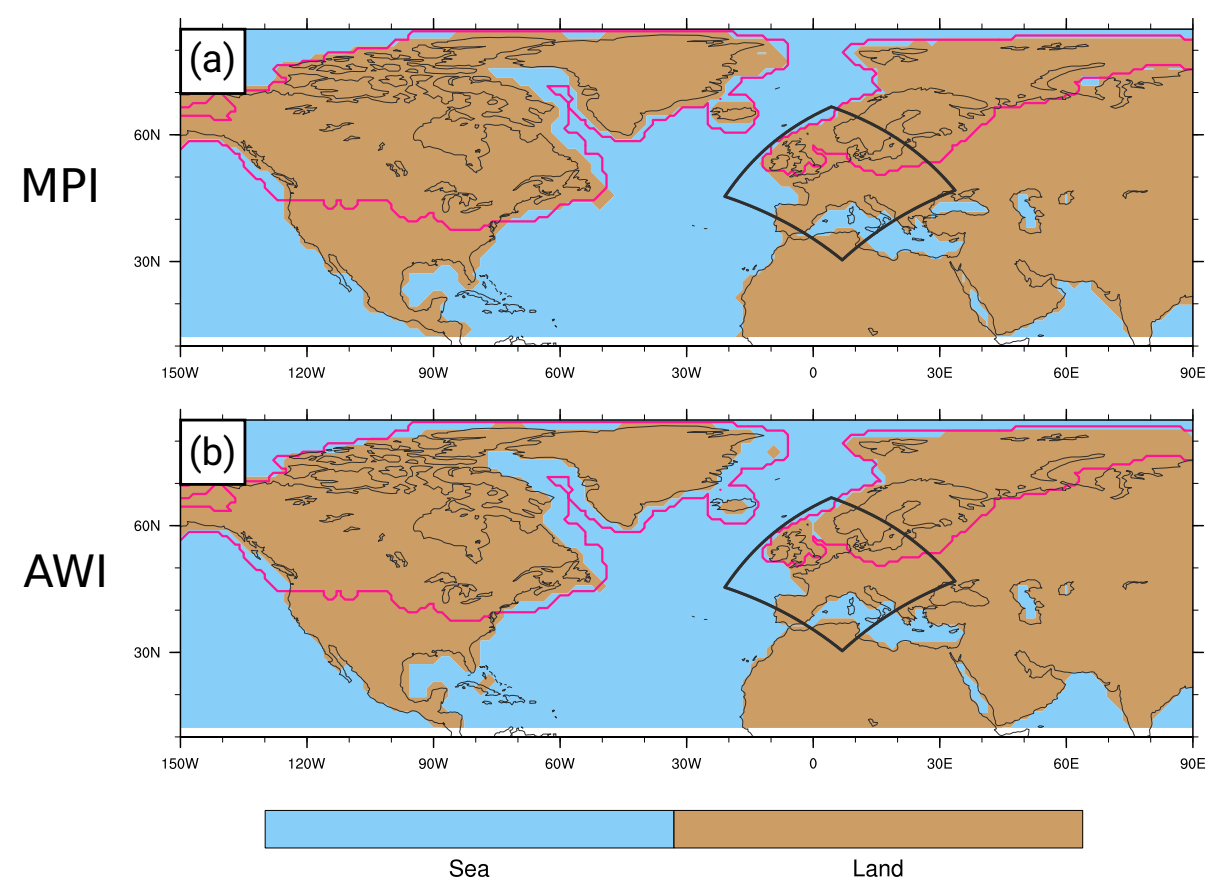

Figure S1. GCM land and sea distribution of the MPI $(a)$ and the AWI simulation $(b)$. Thick black line: WRF Domain 1, thin black line: LGM coastline, pink line: LGM ice sheet. 

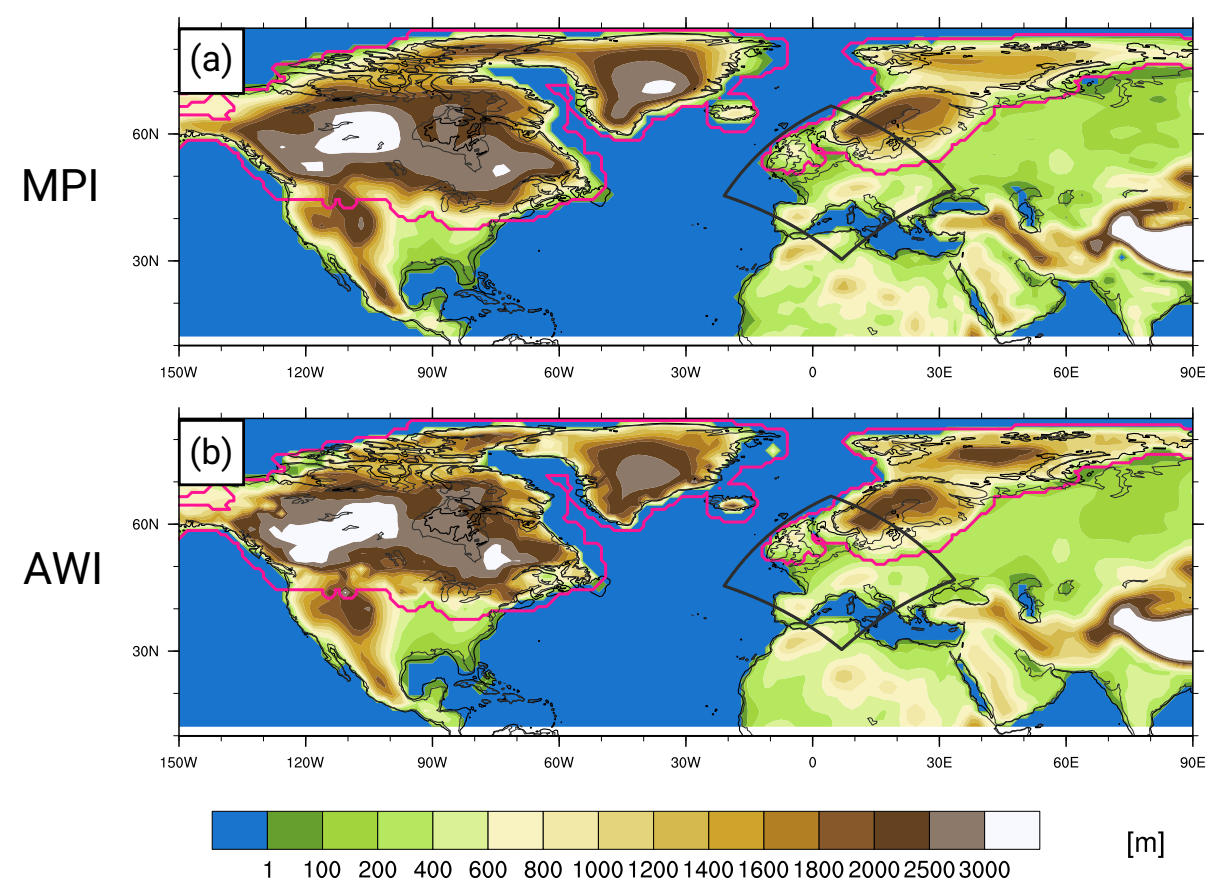

Figure S2. GCM orography of the MPI $(a)$ and the AWI simulation $(b)$. Thick black line: WRF Domain 1, thin black line: LGM coastline, pink line: LGM ice sheet. 


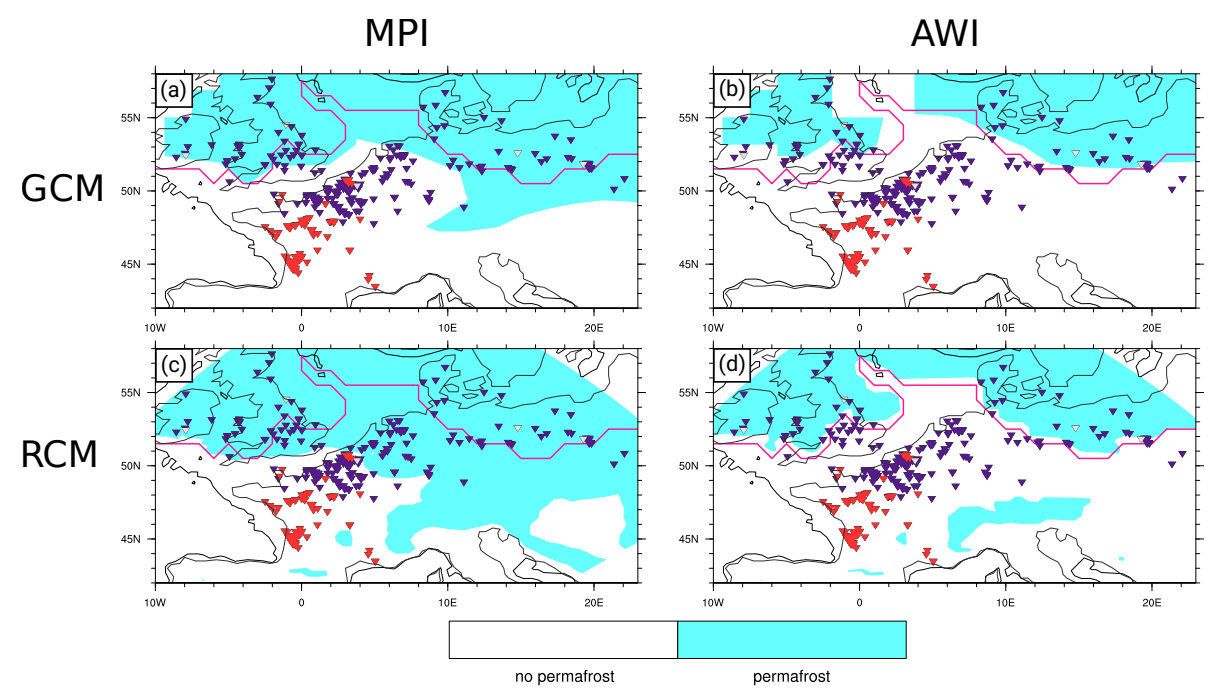

Figure S3. Permafrost distribution based on the annual mean soil temperatures below $0{ }^{\circ} \mathrm{C}$ in approximately $70 \mathrm{~cm}$ depth as simulated by the global MPI $(a)$ and the global AWI simulation $(b)$ and their respective regional counterpart ( $c$ and $d$ ). Ice wedge pseudomorphs, composite, and sand wedges from Andrieux et al. (2016) and Isarin et al. (1998) are denoted by purple, grey, and red triangles respectively. Black line: LGM coastline, pink line: LGM ice sheet. 


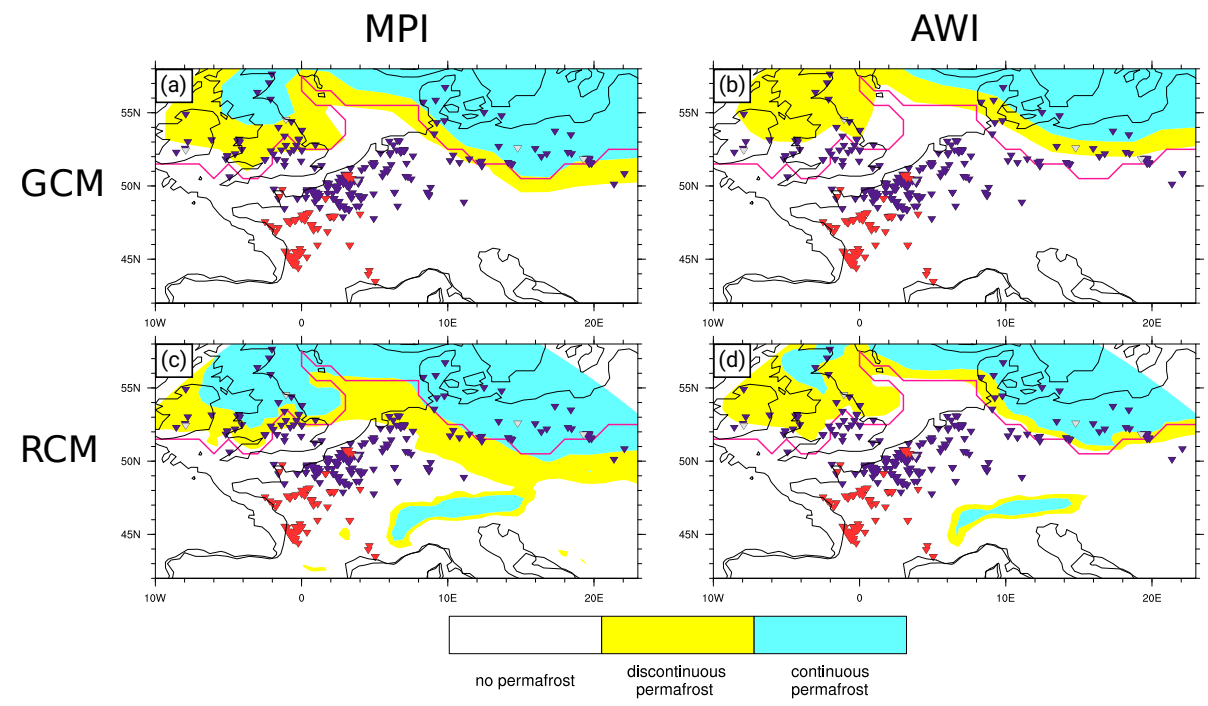

Figure S4. Permafrost distribution based on the mean annual air temperature (MAAT) as simulated by the global MPI ( $a$ ) and the global AWI simulation $(b)$ and their respective regional counterpart ( $c$ and $d$ ). Ice-wedge pseudomorphs, composite, and sand wedges from Andrieux et al. (2016) and Isarin et al. (1998) are denoted by purple, grey, and red triangles respectively. Black line: LGM coastline, pink line: LGM ice sheet. 

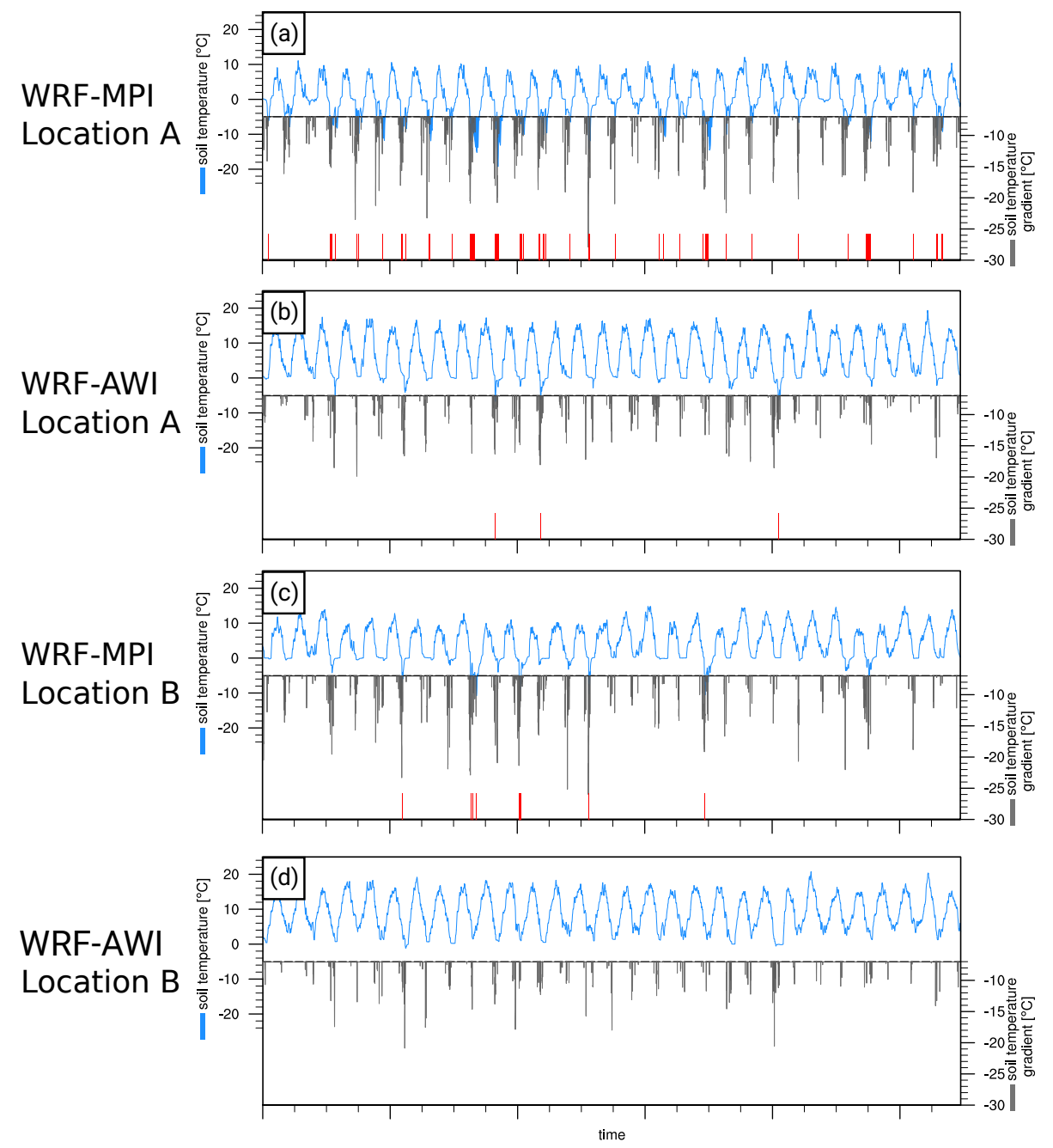

Figure S5. Development of the daily mean soil temperature and soil temperature gradient in location A and B (as denoted in Fig. 1; A: model grid point $49.8^{\circ} \mathrm{N}, 2.49^{\circ} \mathrm{E}$; B: model grid point $\left.46.1^{\circ} \mathrm{N},-0.33^{\circ} \mathrm{E}\right)$ as simulated in WRF-MPI $(a$ and $c)$ and in WRF-AWI $(b$ and $d)$ for 30 consecutive years. Blue lines show the development of the soil temperatures in layer $3(70 \mathrm{~cm})$. When the temperatures fall below $-5^{\circ} \mathrm{C}$, the first condition for thermal contraction cracking after Matsuoka et al. (2018) is fulfilled, marked with blue shading and the reference line. The soil temperature gradient between the first layer $(5 \mathrm{~cm}$ depth) and the third layer (grey shading) is only depicted when condition two after Matsuoka et al. (2018) is fulfilled, with a gradient below $-7^{\circ} \mathrm{C}$. Red lines indicate the coincidence of the two conditions. 